\title{
The Associations between Student-Teacher Relationships and Kindergarten Students' Basic Learning Skills
}

\author{
Hyelin Jeong and Tae-Yeon Kim
}

\begin{abstract}
The purpose of this article was to clarify the associations between student-teacher relationships and kindergarten students' basic learning skills; reading, writing, and math. The subjects were 337 kindergartners and 27 teachers of 22 kindergartens located in Seoul, Gyeonggi, Cheon-ahn, Sejong, Daejeon. The results confirm associations between close student-teacher relationship and basic learning skills; reading and writing. And dependent student-teacher relationship and basic learning skills; math. This article suggests that there are differences in the relationship between teachers involved in reading, writing and math development of young children. Furthermore, it suggests that environmental factors contribute to the learning development of early childhood.
\end{abstract}

Index Terms-Close student-teacher relationship, dependent student-teacher relationship, basic learning abilities, kindergarten.

\section{INTRODUCTION}

Are young children's learning ability born according to a biological timetable or is it shaped by a posteriori learning? The development of learning ability according to the maturational theory passively recognizes the action on the external environment and believes that the young children can learn on his own [1]. In these perspectives, learning abilities have always been regarded as innate abilities in the cognitive domain, such as intelligence, abstract thinking, and memory. On the other hand, the environmentalism including Vygotsky [2] and Bronfenbrenner [3] assumed that the learning ability of the young children can be created through the influence of the external environment, and it has been shown that factors such as parents, teachers, and peers in the classroom can contribute to the enhancement of learning ability.

Early childhood learning ability is estimated mainly through basic learning ability; reading, writing, and math. Generally, studies have used this period as the learning ability of preschoolers, assuming that by the age of five the child's learning ability can be exercised at a basic level [4], [5]. In particular, the longitudinal studies that the basic learning ability of young children measured at this time predicts future academic achievements suggest that the relationship between student and teacher is important [6], [7]. Pianta [8] describes the theory of extended attachment, showing that the relationship between young children and

Manuscript received April 5, 2019; revised July 2, 2019.

Hyelin Jeong is with Seoul National University of Education, Seoul, South Korea (e-mail: jyang0821@ naver.com).

Tae-yeon Kim was with Duksung Women's University, Seoul, South Korea (e-mail: achishis@naver.com). teachers can affect learning ability. According to an extended attachment perspectives, there are three types of relationships; Closeness, Conflict, Dependency. Closeness means that young children and teachers interact positively in showing affectionate and receptive relationships. The intimate interaction between teachers and young children is positive for children and provides a supportive atmosphere to sustain co-awareness, thereby increasing the rate of participation in classroom activities [9]. In addition, positive and intimate relationships are related to cognitive domains such as attention, memory, intelligence, and problem solving within the classroom [10]. However, Conflicts mean an unbalanced relationship between young children and teacher. The conflict relationships predict lower academic achievement [11], [12]. Dependent relationships describe that the young children react mal-adaptively to the situation separated from the teacher and only has a relationship with the homeroom teacher rather than interacting with other teachers or peers.

The extended attachment theory for the relationship between infant teacher relationship and basic learning ability suggests that showing close and reciprocal relationships with teachers in particular provides stable learning opportunities for infants, which can have a positive effect on basic learning skills such as reading, writing, and math. However, infants who have conflicting relationships with teachers may have more difficulty than having frequent learning opportunities because they usually conflict with teachers. Accordingly, studies suggest that conflicting relationships with teachers can have a negative effect on the childens' basic learning ability, and in particular, such conflicting relationships can give an aggressive representation to young childrens and should be taken care[13], [14].

Self-determinination theory [15] also explains the association between student and teacher and academic achievements. In these theories, for students to become motivated the need for relatedness, competence, and autonomy should be fulfilled. If students' basic needs are met, their engagement in learning would be increasing [16]. Unlike the extended attachment theory, this perspective can provide an alternative to dependent relationships.

However, the study of learning ability [17], [18] didn't explore the components of the relationship between the young children and the teachers, and we can see the difference in how teachers interact with each other's abilities none. Therefore, this study seeks to investigate the relationship between early childhood teacher relationship and basic learning ability separately, and to investigate how young children have influence on reading, writing, and mathematical development. For this purpose, this study 
attempts to solve the associations between student-teacher relationship and kindergarten students' basic learning skills.

\section{METHOD}

\section{A. Sample}

The participants comprise of 400 kindergarten students located in Seoul, Gyeong-gi, Cheon-ahn, Sejong, Daejeon, South Korea. To conduct basic learning tests, only five-year-olds were selected from among young children and 200 boys and girls from 22 kindergartens who agreed to participate in the study were selected. A total of 337 children, 174 boys and 163 girls, were selected as final study subjects, excluding 63 young children who wished to discontinue during the test. The average age of kindergarten students ranged from 72 months to 84 months, compared with 78.6 months for boys and 80.3 months for girls. The family economic level of young children who participated in the study were generally above the middle class. There are three subcategories of whether an individual student's relationship is intimate, conflicted or dependent. The questionnaire is measured on a teacher-based, and it takes about 10 minutes for each student.

\section{B. Instruments}

\section{1) Student-teacher relationship}

The prior research of student-teacher relationships [19] has highlighted relationships based on attachment model [20] with parents. On the basis of the attachment model, Pianta [8] designed the Student-Teacher Relationship Scale (STRS) to measure how homeroom teachers perceive relationships with individual students. Each question is measured on a five-point scale from one point of "not at all" to five points of "very yes."

The closeness measures whether teachers perceive their relationship with the student as a friendly and affectionate relationship so that they often have open conversations with each other. The items in this type totaled 11 questions, with the score distribution ranging from 11 to 55 points. Cronbach's $\alpha$ in the closeness was .86 .

The conflict suggests that the interaction between teachers and students continues to cause conflicts, with their opinion differences The number of items in the conflict area totaled 12 , showing the distribution of scores of 12 to 60 . Cronbach's $\alpha$ in the conflict was .90 .

The dependent means conditions in which students interact only with teachers and don't mix well with other teachers or peers. The items consist of a total of five questions, with scores distributed within five to 25 points. Cronbach's $\alpha$ in the closeness was 78 .

\section{2) Basic learning skills test}

Basic learning tests conducted in early childhood are a basic function for learning curriculum after elementary school admission [21], mainly measuring reading, writing, and math. In particular, the areas of reading, writing and calculating have a lasting impact on learning skills after childhood, according to the results proven through longitudinal studies [6]. Based on this theoretical support, this study intended to measure the learning ability of Korean infants in reading, writing and calculating areas, and used the Korean Wechsler Fundamentals: Academic Skills [22]. The test was developed through standardization after modifying the question items of reading, writing and math to reflect Korean kindergarten and elementary education courses.

This test can be applied to children from 5 years and 0 months to 3 grades in elementary school and uses separate or summing items for reading, writing and math scores according to the purpose of the study. We looked at the results of the reading, writing and math tests separately in order to understand the relationship between the student teacher relationship and the sub-area of basic learning ability.

The test is conducted by trained researchers and one-on-one with young children in principle. A pre-test was conducted on 26 5-year-old children based on a manual on the corresponding test. After fully understanding the contents of the test process, the main test was started one-on-one with the young children in a quiet space in their kindergarten. The time required for the test was about 20 minutes per child, depending on the level of their ability.

Reading measures whether a word card of one A4 paper size presented by the researcher can be read in the correct pronunciation in the prescribed order. A word card consists of a total of 70 words and is measured within the range of 0 to 70 points, calculated as 1 point when read with correct pronunciation. If the child fails to answer 10 consecutive questions on the corresponding terminal card, the test shall be aborted. The time required for inspection was about 7 minutes, and Cronbach's $\alpha$ was .87 .

Writing test is written by the child in the test paper and scored by the researcher. Young children receive consonants, vowels, and words from researchers and can be measured up to 40 questions depending on their level. Just like a reading test, if the child fails to take more than 10 questions, stop the test. Each item was calculated for a total of 40 points, with a range of 0 to 40 points. The time required for the writing test was about 10 minutes, and Cronbach's $\alpha$ was .75 .

Math test, as in the writing test, young children write numbers directly on the test paper and calculate the incidental operation. The researcher calls the number to the child and observes if it can be written, and scores it on the questions of calculation. It consists of a total of 31 questions and is calculated one point per question. The score ranges from 0 to 31 and takes about 3 minutes. Cronbach's $\alpha$ in the math was .85 .

\section{Procedure}

The research was carried out from October 2016 to March 2017 through the preliminary survey of the scale, the selection of kindergarten, the participation of research participants, the original survey to be used for data analysis. In order to conduct a preliminary survey on the scale, we conducted a basic learning test on 26 young children aged 5 years old at a kindergarten in S Elementary School located in Daejeon in October 2016. The researchers conducted one-on-one tests with child during free play and break times in the kindergarten's quiet space by familiarizing them with manual instructions based on training on the basic learning skill test. 
Next, we conducted Internet searches such as 'Kindergarten information' with the cooperation of education office officials for about a month from November 2016 in order to invite kindergarten students and teachers. We checked the list of kindergartens in each area, selected a total of 50 kindergartens and made phone calls individually. Also, in some kindergartens, we visited there and met agreements with the principals and teachers. Of the 50 kindergartens, 34 were in Seoul, Gyeonggi, Cheonan, Sejong, Daejeon, Daegu and Busan, but excluding 12 kindergartens that failed to obtain consent from class homeroom teachers and young children's parents. As a result, a total of 400 infants from 22 kindergartens will be selected.

The survey was conducted on selected kindergartens from November 2016 first, and on kindergartens that had delayed the agreement process until February 2017. The researcher visited the kindergarten and conducted basic learning and teacher questionnaire tests on the basis of students and teachers who agreed to participate in the study. The researcher played a simple game to create a comfortable atmosphere for children before conducting the study test, and also told them that young children could stop immediately if they wanted to.

The student teacher relationship questionnaire was conducted by accepting the opinions of the class homeroom teacher. In addition, a questionnaire was issued to the caregiver of the child who agreed to participate in the study to check the level of the child's socio-economic status.

\section{Analytic Plan}

The data collected to determine the relationship between kindergarten 5-year-old infants' relationship with teachers and basic learning skills were statistical in the SPSS 20.0 program.

First, frequency and percentage were calculated using a technical statistical analysis to understand the demographic background and student teacher relationship and basic learning test scores. In addition, Cronbach's $\alpha$ was calculated to identify the reliability between the questions of the student teacher relationship and basic learning test.

Next, Pearson's correlation coefficient was conducted to verify the correlation between child teacher relationship and basic learning ability.

Finally, on the basis of the correlation calculation values between factors, a multiple regression analysis was conducted to determine the relative influence of the student teacher relationship on the basic learning ability of the kindergarten student.

\section{RESUlTS AND DisCUSSION}

\section{A. Reading}

The relative influence of student teacher relationships on reading ability is shown in Table I. Independent variables of closeness, dependency, and conflict with respect to an kindergarten students' reading ability have been shown as significant predictors that account for $6.8 \%$ of the total variation $(F=6.054, p<.001)$. Specifically, only closeness among the factors of the student teacher relationship was a static predictor that was significant to the child's reading ability $(\beta=.179, p<01)$. These results mean that a close relationship between student and teacher can have a positive effect on the child's reading ability.

TABLE I: REGRESSION ANALYSIS RESULTS IN READING

\begin{tabular}{lllllll}
\hline \hline $\begin{array}{l}\text { Independent } \\
\text { factors }\end{array}$ & $B$ & $S E$ & $\beta$ & $t$ & $\Delta R^{2}$ & $F$ \\
\hline (Constant) & 19.829 & 9.994 & & $1.984^{* *}$ & & \\
SES & 1.576 & .449 & .190 & $3.510^{* *}$ & & \\
Closeness & .491 & .171 & .179 & $2.874^{* *}$ & .068 & ${ }^{* .054}$ \\
Dependency & -.121 & .270 & -.030 & -.449 & & \\
Conflict & .054 & .147 & .025 & .365 & & \\
\hline \hline & \\
$p<.05,{ }^{* * *} p<.01,{ }^{* * *} p<.001$ & & & & &
\end{tabular}

\section{B. Writing}

The relative influence of the student teacher relationship on the writing ability of the kindergarten student is shown in Table II. Young children's writing ability has been shown as a significant predictor of the independent variable in the student teacher relationship, which accounts for $7.5 \%$ of the total variation $(F=6.727, p<.001)$. In particular, close infant teacher relationships have been shown to be significant positive predictors for the writing abilities of young children $(\beta=.170, p<.01)$. This means that a close relationship between student and teacher can have a positive effect on the child's writing ability.

TABLE II: REGRESSION ANALYSIS RESULTS IN WRITING

\begin{tabular}{lllllll}
\hline \hline $\begin{array}{l}\text { Independent } \\
\text { factors }\end{array}$ & $\mathrm{B}$ & $\mathrm{SE}$ & $\beta$ & $t$ & $\Delta R^{2}$ & $\mathrm{~F}$ \\
\hline (Constant) & -3.706 & 4.054 & & -.914 & & \\
SES & .762 & .182 & .226 & $4.184^{* * *}$ & & \\
Closeness & .190 & .069 & .170 & $2.747^{* *}$ & .075 & 6.72 \\
Dependency & -.147 & .110 & -.089 & -1.341 & & \\
Conflict & .056 & .060 & .065 & .943 & & \\
${ }^{*} p<.01,{ }^{* * * *} p<.001$ & & & & &
\end{tabular}

\section{Math}

As shown in Table II, math ability has been shown as a significant predictor of the independent variable in the student teacher relationship, which accounts for 3.0\% of the total variation $(F=2.574, p<.05)$. As for young children's math ability, only dependent student teacher relationships were found to be significant negative predictors $(\beta=-.173, p$ $<.05)$. It means that the relationship between dependent students and teachers can negatively affect the kindergarten student's ability to math.

TABLE III: REGRESSION ANALYSIS RESULTS IN MATH

\begin{tabular}{lllllll}
\hline \hline $\begin{array}{l}\text { Independent } \\
\text { factors }\end{array}$ & $\mathrm{B}$ & $\mathrm{SE}$ & $\beta$ & & $\Delta R^{2}$ & $\mathrm{~F}$ \\
\hline (Constant) & 3.370 & 1.696 & & $2.199^{*}$ & & \\
SES & .123 & .076 & .089 & 1.609 & & \\
Closeness & .047 & .029 & .103 & 1.622 & .018 & $2.574^{*}$ \\
Dependency & -.118 & .046 & -.173 & $-2.561^{*}$ & & \\
Conflict & .024 & .025 & .067 & .949 & & \\
\hline${ }^{*} p<.05$ & & & & & &
\end{tabular}




\section{CONCLUSION}

The purpose of this study was to investigate between the student teacher relationship and young children's basic learning ability.

First, close and affectionate relationships with teachers could have a positive impact on reading ability. This finding is consistent with the results of a study that suggests that a positive, supportive, and close relationship with a child can enhance academic achievement (Buyse et al., 2009; Hamre \& Pianta, 2001; Roorda et al., 2011) [23], [24]. And this is similar to the result that closeness between early childhood teachers improves acceptance of vocabulary including reading [25], [26]. The close relationship reflecting the smooth communication with the teacher provoked the promotion of reading ability. That is, communication that reflects teacher's speech, facial expressions, and emotions in early childhood education institutions has a great impact on language-related learning activities by giving children a natural language instruction [27]. Especially, reactive and affectionate interaction between children and teachers has a positive effect on language development [28]. For example, if a teacher uses open questions for young children and shows interactions that facilitate extended thinking, the child's vocabulary and problem-solving skills can be increased [18]. Pianta [8] who developed a measure of student-teacher relationships, explain that teachers' heavy use of high-level dialogue and open questions for students constitute a close relationship. In other words, even when reading the book with the young children, the teacher kindly informs them of the words or questions that the students didn't know, and interacting can raise the level of the degree of learning by increasing the motivation for young children's reading learning.

Second, close relationship with a teacher can be an important factor in writing ability. This is based on a holistic view of learners' writing development, consistent with the result that learners' writing skills can develop when teachers interact positively with students [29]. Sulzby [30] argued that the development of a child's writing ability is developmental rather than a gradual one, but that a writing at one level is a developmental form that appears with the writing of the upper or lower level. This suggests that children can develop their writing skills through interaction with teachers in the real life environment they experience. From this point of view, it can be inferred that the child's writing also contributes to the natural writing development by encouraging the teacher and intimately interacting with the child so as to increase confidence in the writing level of the child. This means that 5-year-olds mainly use invented writing, which allows them to write fluently by emphasizing writing behavior rather than accuracy.

Especially, most kindergartens in South Korea encourage early childhood writing activities in an integrated and experiential way. It encourages young children to engage in interesting and curious writing activities that are required for practical situations rather than formal and repetitive teaching [31]. Therefore, it is suggested that the writing activities of young children in kindergartens are more important to provide scaffolding to provide the necessary feedback to the children based on the close relationship.
Third, the ability of the child to math is related to the dependency relation between student and teacher, and the dependency has negative relation with math. These results are in part consistent with the findings that the relationship between infant and teacher influences mathematical competence [17], [18]. But, recent studies [32] on young children have shown no relevance, and a concise explanation of the results of this study is needed. Similar to reading and writing skills, mathematics also supports teachers' use of mathematical terms in mathematics, and interaction to elaborate mathematical responses positively affects infant mathematical ability [33]. And appropriate feedback between student and teacher helps with mathematical ability [34]. On the whole, these studies generally refer to the intimate interaction of mathematics teachers applied to infants or open questions directly affecting mathematical ability.

However, in this study, children can only influence their math abilities from having dependent relationships with teachers, especially independent relationships with teachers have affected their high-level math abilities. Thus, in this study, this relationship is explained according to the process of self-determination theory [15]. According to these theories, students are synchronized according to the basic psychological needs; the needs for relatedness, for competence, and autonomy. It is important that teachers support autonomy, including giving students freedom to make their own choices and showing connections between schoolwork and students' interests. Specifically, if the teacher meets the basic needs of students, participation in learning also increases to show a high level of learning ability [16].

This position can also be explained from a constructivism perspective on early childhood education. The constructivist view, which focuses on the process of shaping knowledge based on infant autonomy, emphasizes that the process of learning must involve the process of inventing and self-organizing [35]. Especially, the mathematical domain which shows the ability of children to explore numbers voluntarily and to understand and infer the principle has more influence in explaining the principles of learning from a constructivist point of view. Thus, it can be interpreted that the autistic desire required for mathematics learning is not satisfied in the case of a child dependent on the teacher, and the voluntary search or inventive activity necessary for the mathematical learning is not performed.

The limitation in this study is that it was restricted to students who were the age of 5 only and longitudinal study will be useful for future research. And it should also be possible to add to the use of other measures that can supplement objectivity by relying on teacher questionnaires on early childhood teacher relationships.

\section{CONFLICT OF INTEREST}

The authors declare no conflict of interest.

\section{AUTHOR CONTRIBUTIONS}

Hyelin Jeong conducted the research; Taeyeon Kim analyzed the data; Hyelin Jeong and Taeyeon Kim wrote the paper. 


\section{REFERENCES}

[1] A. Gesell, The First Five Years of Life, New York: Harper, 1940.

[2] L. S. Vygotsky, Mind in Society: The Development of Higher Mental Processes, Cambridge, MA: Harvard University Press, 1978.

[3] U. Bronfenbrenner, The Ecology of Human Development: Experiments in Nature and Design, Cambridge, MA: Harvard University Press, 1979.

[4] K. L. Paro and R. C. Pianta, "Predicting children's competence in the early school years: A meta-analytic review," Review of Educational Research, vol.70, no. 4, pp. 443-484, 2001.

[5] J. A. Welsh, R. L. Blair, K. L. Bierman, and K. E. Nelson, "The development of cognitive skills and gains in academic school readiness for children from low-income families," Journal of Educational Psychology, vol. 102, no. 1, pp. 43-53, 2010.

[6] G. J. Duncan, C. J. Dowsett, A. Claessens, K. Magnuson, A. Huston, C. Klebanov, and H. Sexton, "School readiness and later achievement," Developmental Psychology, vol. 43, no. 6, p. 1428, 2007.

[7] A. J. Mashburn and R. C. Pianta, "Social relationships and school readiness," Early Education and Development, vol. 17, no. 1, pp. 151-176, 2006

[8] R. C. Pianta, "Student-teacher relationship scale: Professional manual," Psychological Assessment Resources, 2001.

[9] T. Striano and D. Stahl, "Sensitivity to triadic attention in early infancy," Developmental Science, vol. 8, no. 4, pp. 333-343, 2005.

[10] L. M. Justice, E. A. Cottone, A. Mushburn, and S. E. Rimm-Kaufman, "Relationship between teachers and preschoolers who are at risk: Contribution of children's language skills, temperamentally based attributes, and gender," Early Education and Development, vol. 19, no. 4, pp. 600-621, 2008.

[11] D. M. Decker, D. P. Dona, and S. L. Christenson, "Behaviorally at-risk African American student: The importance of student-teacher relationships for student outcomes," Journal of School Psychology, vol. 45, no. 1, pp. 83-109, 2007.

[12] A. S. Eisenhower, B. L. Baker, and J. Blacher, "Early student-techer relationships of children with and without intellectual disability: Contributions of behavioral, social, and self-regulatory competence,' Journal of School Psychology, vol. 45, no. 4, pp. 363-383, 2007.

[13] D. Berry, "Inhibitory control and teacher-child conflict: Reciprocal associations across the elementary-school years," Journal of Applied Developmental Psychology, vol. 33, pp. 66-76, 2011.

[14] R. D. McKinnon and C. B. Blair, "Family life project investigators," Executive Function and Teacher-Child Relationships from Prekindergarten to Second Grade: A Longitudinal Analysis, 2017.

[15] E. L. Deci, R. J. Vallerand, L. G. Pelletier, and R. M. Ryan, "Motivation and education: The self-determination perspective," Educational Psychologist, vol. 26, pp. 325-346, 1991.

[16] E. A. Skinner and M. J. Belmont, "Motivation in the classroom: Reciprocal effects of teacher behavior and student engagement across the school year," Journal of Educational Psychology, vol. 85, pp. 571-581, 1993.

[17] M. R. Burchinal, E. Peisner-Feinberg, R. C. Pianta, and C. Howes, "Development of academic skills from preschool through second grade: Family and classroom predictors of developmental trajectories," Journal of School Psychology, vol. 40, no. 5, pp. 415-436, 2002.

[18] T. W. Curby, J. LoCasale-Crouch, T. R. Konold, R. C. Pianta, C. Howes, and O. Barbarin, "The relations of observed pre-K classroom quality profiles to children's achievement and social competence,' Early Education and Development, vol. 20, no. 2, pp. 345-372, 2009.

[19] R. C. Pianta, B. Hamre, and M. Stuhlman, Relationships between Teachers and Children, Hoboken, NJ: Wiley Online Library, pp. 199-234, 2003

[20] J. Bowlby, Attachment and Loss: Vol. 1. Attachment, New York, NY: Basic Books, 1969

[21] T. G. Devine, Teaching Study Skills. A Guide for Teachers, Newton, MA 02159, 1987.

[22] S. H. Hong, S. T. Hwang, J. H. Kim, J. K. Park, and Y. J. Jang, "Standardization of the K-WFA(Korean Wechsler Fundamentals: Academic Skills)," Korean Journal of Clinical Psychology, 2015.

[23] E. Buyse, K. Verschueren, P. Verachtert, and J. V. Damme, "Predicting school adjustment in early elementary school: Impact of teacher-child relationship quality and relational classroom climate." The Elementary School Journal, vol. 110, no. 2, pp. 119-141, 2009.

[24] D. L. Roorda, M. Y. Helma, J. L. Joomen, and F. J. Oort, "The influence of affective teacher-student relationships on students' school engagement and achievement: A meta-analytic approach," Review of Educational Research, vol. 81, no. 4, pp. 493-529, December, 2011.

[25] R. C. Pianta and M. W. Stuhlman, "Teacher-child relationships and children's success in the first years of school," School Psychology Review, vol. 33, no. 3, p. 444, 2004.

[26] J. L. Spilt and H. M. Y. Koomen, "Widening the view on teacher-child relationships: Teachers' narratives concerning disruptive versus non-disruptive children," School Psychology Review, vol. 38, pp. 86-101, 2009

[27] D. K. Dickinson and V. M. Porche, "Relation between language experiences in preschool classroom and children's kindergarten and fourth-grade language and reading abilities," Child Development, vol. 82 , no. 3, pp. 870-886, 2011.

[28] C. M. Connor, S. H. Son, A. H. Hindman, and F. J. Morrison, "Teacher qualifications, classroom practices, family characteristics, and preschool experience: Complex effects on first graders' vocabulary and early reading outcomes," Journal of School Psychology, vol. 43, no. 4, pp. 343-375, 2005.

[29] E. Hatch, Discourse \& Language Education, Cambridge: Cambridge University Press, 1992

[30] E. Sulzby, “Children's emergent reading of favorite storybooks: A developmental study," Reading Research Quarterly, vol. 20, pp. 459-481, 1985

[31] C. S. Lee, "A critical review of writing instruction for young children," International Journal of Early Childhood Education, vol. 18, no. 1, pp. 69-88.

[32] R. D. McKinnon and C. Blair, "Bidirectional relations among executive function, teacher-child relationships, and early reading and math achievement: A cross-lagged panel analysis," Early Childhood Research Quarterly, vol. 46, no. 1, pp. 152-165.

[33] B. D. Cooke and D. Buchholz, "Mathmatical Communication in the classroom: a teacher makes a difference," Early Childhood Education Journal, vol. 32, no. 6, pp. 365-369, June, 2006.

[34] A. K. Jitendra and E. J. Kameenui, "Experts' and novices' error patterns in solving part-whole mathematical word problems," The Journal of Educational Research, vol. 90, no. 1, pp. 42-51, July 2010.

[35] C. Kamii, Young Children Continue to Reinvent Arithmetic, New York: Teacher College Press, 1989.

Copyright (C) 2019 by the authors. This is an open access article distributed under the Creative Commons Attribution License which permits unrestricted use, distribution, and reproduction in any medium, provided the original work is properly cited (CC BY 4.0).

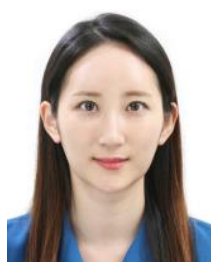

Hyelin Jeong was born in South Korea in 1985. She obtained her Ph.D at Seoul National University, South Korea in 2017. Her doctoral thesis was about young children's school readiness in the transition from early childhood education to elementary education, related to kindergarten educational environment. She worked as part time instructor at Woosong University, Duksung Women's University, and Seoul National University of Education from 2016 to 2018. She currently is a visiting professor of the Department of early childhood education in Seoul National University of Education. Her research interests include children's moral development, children's educational environment and the education of special children.

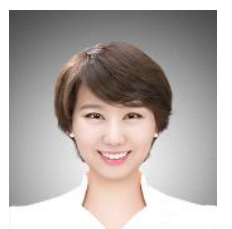

Tae Yeon Kim was born in South Korea in 1980. She obtained her Ph.D at Seoul National University, South Korea in 2013. Her doctoral thesis was about children's attention-related EEG and story comprehension, related to reading media types and audio-visual feedback in electronic books. She worked as member of G-learning (Game based learning) elementary school test operation team at Contents Management Lab from 2009 to 2013.

She also worked as a training researcher at Research Institute of Human Ecology at Seoul National University in 2014. She currently is a researcher of Evergreen Child Development Institute, and an adjunct professor of the Department of Child Development and Family Studies in Duksung Women's University. Her research interests include children's language development, children's electric device using and the education of pre-service childcare centre teachers. 